\title{
FERNANDO PESSOA, SÁ-CARNEIRO E CÔRTES- RODRIGUES, O TRIÁLOGO EM ORPHEU
}

\author{
FERNANDO PESSOA, SÁ-CARNEIRO AND CÔRTES- \\ RODRIGUES, THE TRIALOGUE IN ORPHEU
}

\author{
Anabela Almeida*
}

Resumo: No final da vida, Fernando Pessoa evoca Armando Côrtes-Rodrigues como quem é "diretamente de Orpheu" e Violante de Cysneiros, personalidade literária do poeta açoriano, "uma maravilha subtil de criação dramática". Neste artigo, apresentamos factos que estarão na base destas afirmações: o diálogo que em tempo de Orpheu, ou seja entre 1912 e 1916, o poeta açoriano estabeleceu com Fernando Pessoa e Mário de Sá-Carneiro, os coração e cérebro da revista, e a singularidade de Violante de Cysneiros no universo heteronímico.

Palavras-chave: Fernando Pessoa, Mário de Sá-Carneiro, Armando Côrtes-Rodrigues, Violante de Cysneiros, Orpheu, Sudoeste.

Aвstract: At the end of his life, Fernando Pessoa evokes Armando Côrtes-Rodrigues as who is "directly from Orpheus" and Violante de Cysneiros, literary personality of the Azorean poet, "a subtle wonder of dramatic creation." In this article, we present facts that will be the base of these affirmations: the dialogue made in the era of Orpheu, between 1912 and 1916, the Azorean poet established with Fernando Pessoa and Mário de Sá-Carneiro, the heart and brain of the magazine, as well the singularity of Violante de Cysneiros in the heteronymic universe.

Keywords: Fernando Pessoa, Mário de Sá-Carneiro, Armando Côrtes-Rodrigues, Violante de Cysneiros, Orpheu, Sudoeste.

\footnotetext{
"Professora de Português do ensino básico e secundário, tem, nesta qualidade, realizado e promovido formação e desempenhado cargos de coordenação e supervisão pedagógica. Doutorada em Estudos de Literatura pela Universidade Nova de Lisboa, com a tese As constantes de Orpheu na obra de Armando Côrtes-Rodrigues, tem, nesta área, proferido comunicações e publicado artigos em revistas de literatura e cultura. Membro do grupo IEMO. E-mail: annabelaalmeida@ gmail.com
} 
Em novembro de 1935, quando passavam vinte anos sobre Orpheu e no mês em que morre Fernando Pessoa, sai o terceiro e último número da revista Sudoeste. Este número, organizado por Almada Negreiros e Fernando Pessoa, pretendia reunir textos de todos os colaboradores de Orpheu. Porém, por razões de ordem geográfica, não foi possível integrar a participação de Ronald de Carvalho, Eduardo Guimaraens e Côrtes-Rodrigues, conforme explica Fernando Pessoa no já mítico texto, "Nós, os de Orpheu".

Neste texto de uma página que antecede aquelas colaborações, Fernando Pessoa considera a personalidade inventada de Violante de Cysneiros e os seus poemas «uma maravilha subtil de criação dramática» e apresenta Côrtes-Rodrigues como quem é «diretamente de Orpheu».

E, com efeito, assim é.

Armando Côrtes-Rodrigues chegou a Lisboa para cursar Letras no dia 6 de outubro de 1910, a capital não poderia ter sido uma boa anfitriã, no entanto, o poeta lembraria o tempo que nela viveu como a melhor recordação da sua vida. Aqui conheceu, entre outros, Mário de Sá-Carneiro, Almada Negreiros, Hernâni Cidade, Alfredo Guisado e António Cobeira, que o apresentou a Fenando Pessoa como quem chegava da ilha de Antero.

Os companheiros que o poeta açoriano conheceu, que se revelaram amigos de vida e poesia, foram, pois, decisivos para a construção daquela grata lembrança. No entanto, outros aspetos contribuiriam para que o tempo que Côrtes-Rodrigues viveu em Lisboa o acompanhasse pela vida fora. As livrarias que frequentou, repletas de livros e de novidades literárias, foram outro elemento de deleite do poeta, tendo assistido à inauguração da Livraria Sá da Costa com cujo proprietário manteve diálogo durante décadas. Este jovem estudante, que recebera uma sólida formação musical e tinha na casa paterna ambiente onde reinava a Música, não foi indiferente ao que, com esta arte, se passava na capital; tendo assistido a muitos concertos nos teatros S. Carlos e República, alguns dos quais na companhia de Fernando Pessoa, conforme consta no Diário do poeta plural.

Leiamos o que Côrtes-Rodrigues disse ao lembrar, em 1953, este tempo de há 100 anos:

Guardo esses cinco anos de convívio diário na intimidade do belo espírito do grande poeta como a melhor recordação da minha vida. De resto, nunca conheci ninguém de tão vasta cultura e de tão penetrante inteligência que fosse mais simples, mais acolhedor, mais delicado, mais correto e menos dogmático do que ele, que bem poderia servir de exemplo a certos partidarismos literários. Magro, extremamente reservado, o poeta possuía uma magnífica memória, que lhe permitia recitar poetas franceses e ingleses e invariavelmente aquele poema de Camilo Pessanha que começa: "Chorai arcadas/ de violoncelo/convulsionadas...”. Abancávamos na "Brasileira" do Chiado ou do Rossio durante o dia, com um grupo de amigos, que já pressentia o génio desse homem que tinha, no seu ar de mistério, qualquer coisa de iluminado, com olhos penetrantes que olhavam, para além dos óculos, o enigma das almas e do mundo. (CÔRTES-RODRIGUES, 1953)

Durante estes cinco anos, o homem a quem, nestes termos, Côrtes-Rodrigues se 
refere, Fernando Pessoa, elabora e inicia o seu projeto literário, que, no seu caso, é projeto de vida, que o revelaria como um "criador de cultura e civilização". Colabora na Águia, na Teatro, na Renascença e em outras revistas e jornais com artigos de intervenção em diferentes domínios da vida portuguesa, destacando-se, em 1912, os que teorizam a estética emergente; faz nascer os heterónimos, «mata» um deles, Alberto Caeiro; inicia o Livro do Desassossego; forja e publica a revista Orpheu.

Quanto a Côrtes-Rodrigues, a sua vida, neste tempo, ia acontecendo entre as aulas dos professores Leite de Vasconcelos, Adolfo Coelho ou Teófilo Braga; o quartel, para onde a jovem República o chamou, indiferente ao seu estatuto de estudante, e Algés, onde, a partir de setembro de 1912, mora com a muIher no $\mathrm{n}^{\circ} 20$ da rua da Piedade. Fazia igualmente parte do quotidiano do jovem poeta açoriano as tertúlias nas Brasileiras do Chiado e do Rossio ou no restaurante Irmãos Unidos, estabelecimento propriedade dos pais de Alfredo Guisado, "o Mata-fomes", como estes jovens o chamavam. Os encontros entre Côrtes-Rodrigues e Fernando Pessoa aconteciam, muitas vezes, num café escolhido ao acaso, onde conseguiam maior privacidade, ${ }^{1}$ ou no La Gare, onde redigiu as notas biobibliográficas que este companheiro lhe confiou. Os dias de Côrtes-Rodrigues integravam também as fugidas aos quartos alugados dos amigos Hernâni Cidade ou ao

\footnotetext{
"Mas as horas de maior intimidade com Pessoa eram aquelas que passávamos sozinhos à mesa de um café, onde entrávamos ao acaso", espólio Côrtes-Rodrigues, cota 44, pp.1-2
}

do Sá-Carneiro, para dar a ler a sua escrita e ouvir a dos companheiros,

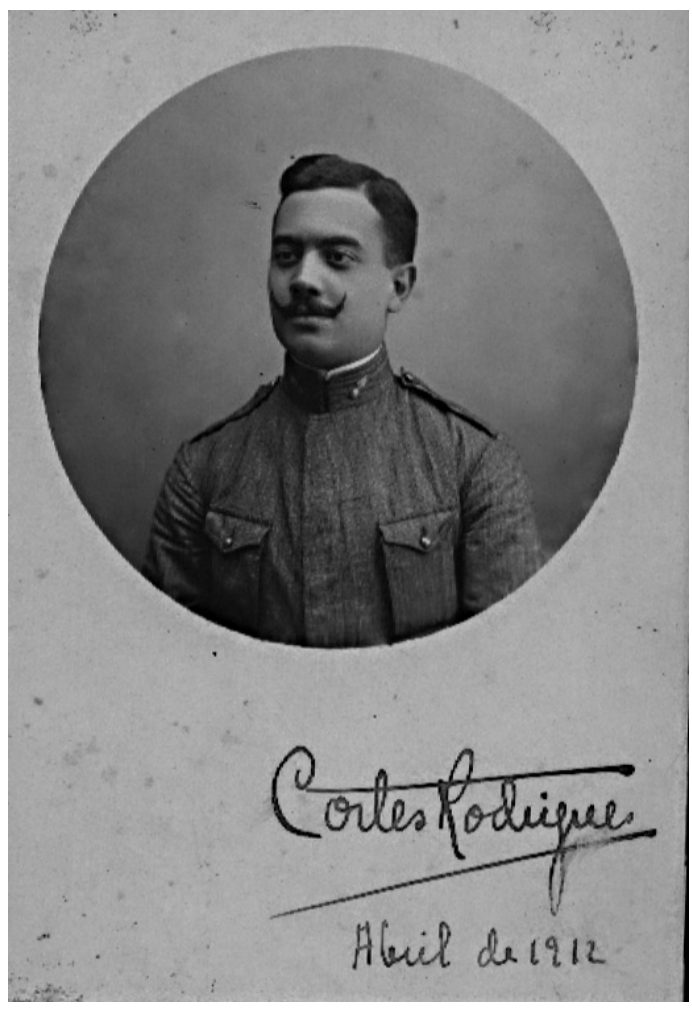

Quando Sá-Carneiro aparecia por Lisboa, vivia no Largo do Carmo, ao pé do convento. Vinha raramente a cafés. Ia vê-lo várias vezes por semana à sua casa e ouvi da boca dele muitas das suas prosas e poemas. Era cheio, corado, com aspeto físico que contrastava com a estranha vibração da sua sensibilidade. (CÔRTES-RODRIGUES, 1953)

Destas leituras chegam-nos registos através de Sá-Carneiro, como este que lemos na carta que envia a Côrtes-Rodrigues, em 23 de março de 1914. Para além deste testemunho, concluímos que Guisado se "irava em magenta" contra o "homo-sexualismo" 
"apoteoso" do Conto, o que para CôrtesRodrigues, se não era natural, pelo menos, aceitava-o naturalmente. Quanto a SáCarneiro esta sua vontade de ver o Guisado "irar-se em magenta", não cremos que adviesse de alguma atitude provocatória, mas, provavelmente, da sua necessidade, legítima, de combater preconceitos e aversões que, seguramente, lhe trouxeram angústia e tristeza.

Então o meu querido Amigo não vai melhor?

Cientemente lastimo a sua carta - não só pela Ausência do confrade e Oiro como, intensamente, por ela se dever a um incómodo físico. Mas não será nada de importância. E breve, esperemos em Deus, os laivos granates de sua garganta se evolarão em Saúde.

Já agora, oiça:

O nosso Alfredo Guisado intersecciona ora por Espanha. No entanto regressará ainda esta semana. Daí preferível a leitura aos meus dois Amigos - tanto mais para você assistir ao espanto desse nosso confrade, fulvo inimigo da doença - e puro, ainda se irando magentamente contra o homo-sexualismo - apoteose do meu Conto, Preveni-loei, portanto, do dia em que tiver combinado com o poeta da Distância (o que será no fim desta semana ou começo da outra) ${ }^{2}$

Estes jovens iam tentando a publicação dos seus textos nas revistas que lhes eram

2 Carta parcialmente editada por Joel Serrão, Seara Nova Seara Nova, Lisboa, XXV, No968, 2/3/1946, p.135 e integralmente publicada por Anabela Almeida in Grotta, Ponta Delgada, $\mathrm{N}^{\circ} 1$, Nov.2016, p.40 próximas. Em 1913, Fernando Pessoa introduz na revista Águia Sá-Carneiro, António Cobeira e Côrtes-Rodrigues; de resto, é aqui que o poeta açoriano vê publicado, pela primeira vez, os seus poemas. António Cobeira faz o mesmo na Ocidente. Nesta revista são publicados poemas de Sá-Carneiro, CôrtesRodrigues, Alfredo Guisado, Fernando Pessoa e do próprio António Cobeira. Porém as incompatibilidades surgem, como sabemos, a cisão com a Águia acontece.

Portanto, a necessidade e vontade destes jovens terem a sua revista, onde pudessem livremente expressar a sua arte, ganha força e começa a germinar. Vários projetos surgem. Primeiro, a revista Lusitânia que, para além dos poemas de Côrtes-Rodrigues, contaria com ele como editor. Depois a Europa que se assume como órgão do Interseccionismo e, como podemos ler no seu índice, o poeta açoriano participaria com "Loucura da Floresta (Página intersecionista)”.

Mais tarde, cinco meses antes de Orpheu, surge a possibilidade de reunir em livro os textos e poemas que estes jovens criavam, "uma Antologia do Interseccionismo". Seria este mesmo o título», conforme consta na carta de Fernando Pessoa a Côrtes-Rodrigues de 4 de outubro de 1914 que, no volume referido, publicaria "poemas e prosas".

Em agosto de 1914 eclode a Guerra e, ainda com o curso por terminar, CôrtesRodrigues parte para S. Miguel com a mulher e o filho, que nasceu neste mês.

Fernando Pessoa, que encontrara na dimensão humana e intelectual do amigo açoriano alguém capaz de o compreender, escreve-lhe estabelecendo a ponte que liga 
o jovem poeta ilhéu ao que vivera naqueles últimos quatros anos. Nestas cartas o poeta plural responde às questões que o amigo lhe coloca, comenta um ou outro aspeto da sua poesia e anima, fala de si e do projeto comum, Orpheu, que em fevereiro de 1915 se realizava, conforme podemos ler na carta do dia 19 deste mês.

Vai entrar amanhã mesmo no prelo. Deve ter perto de 80 páginas, e é trimestral. Se você mandar colaboração para chegar aqui no vapor do princípio do mês que vem era ótimo. Não nos falte. Seria para nós um grande desgosto que a revista aparecesse sem v.[ocê] colaborar (1985, p.57. Destacados do autor).

Mas não é só Fernando Pessoa quem reclama a colaboração do companheiro ilhéu, ela chega-lhe também, em "Suplemento", numa carta de um outro amigo:

\section{Suplemento}

Após há lançado por Europa a guerra ouro e sangue ressurjo em nervos e roxo saudando-o. Mas meu querido Côrtes-Rodrigues é absolutamente necessário, forçoso, imperialmente forçoso que satisfaça o pedido do Pessoa! O original vai amanhã levado por mim à tipografia onde ora se imprime o meu volume Céu em fogo com este sumário "A grande Sombra, Mistério, O homem dos Sonhos, A Estranha Morte do Prof. Antena (a você consagrado), Asas, O fixador de Instantes, Eu-próprio o Outro, Ressurreição”. A revista portanto é irrevogavelmente Certa. Não seríamos nada se, a sua colaboração - pois numa parede heráldica a ausência de um tijolo d'ouro a faz desabar. Envie, por amor De Deus - de mãos postas lhe suplico - a sua áurea colaboração e pelo $1^{\circ}$ vapor.

\section{Sem falta!}

Chuva de abraços do

M. de Sá-Carneiro (ALMEIDA, 2014, p. 44)

Côrtes-Rodrigues não podia, pois, faltar, e envia os seus poemas pelo primeiro vapor que rumou a Lisboa. Mandou "bastantes coisas", "o mais interseccionista" que tinha, “coisas género Outro", conforme sugestão de Pessoa na carta que referimos (1985, p.57). E, assim, a sua participação, depois de selecionada, figurará com cinco poemas: "Abertura do 'Livro da Vida”, "Poente”, "Agonia”, "Só” e "Outro", e, embora os tenha enviado da Ilha, em fevereiro de 1915, todos eles estão identificados com o espaço Lisboa e datados do ano anterior.

O segundo número da revista é organizado com a presença de Côrtes-Rodrigues que em maio regressa a Lisboa para terminar o seu curso. Este número conta, portanto, com a colaboração direta de CôrtesRodrigues, mas não com o seu nome que tinha de ser protegido, no exame, das fúrias que Adolfo Coelho, seu professor e examinador, desenvolvera contra os rapazes da Orpheu.

Foi então que Fernando Pessoa, que muito frequentemente me recomendava a "duplicação da personalidade" (a frase era dele) sugeriu que arranjasse

\footnotetext{
${ }^{3} \mathrm{O}$ original deste poema tem uma palavra diferente. Em Orpheu 1 o último verso da primeira estrofe é "Marcha sinistra a procissão dos monges" e no original está "Marcha sinistra a procissão dos montes".
} 
um pseudónimo de mulher, achando até excelente que aparecesse uma colaboradora entre tantos poetas, guardado o costumado sigilo, para provocar maior curiosidade. E foi ele que escolheu o nome. (CÔRTES-RODRIGUES, 1953)

(...) para uma série de poesias líricas que lhe apresentei (... $)^{4}$

Violante de Cysneiros surgiu, portanto, da necessidade de proteger Côrtes-Rodrigues das retaliações de Adolfo Coelho. Fernando Pessoa sugere o desdobramento feminino, o poeta açoriano aceita-o e escreve na pessoa e em género/sexo outro. Os poemas assim "nascidos" evocam em Pessoa um nome, Violante, e um apelido, Cysneiros. Esta personalidade nasce, portanto, de dois; facto que lhe confere singularidade no eventual universo heteronímico em que a situemos.

Que sabemos de Violante de Cysneiros que é única personalidade literária em Orpheu, a par do seu mestre, Álvaro de Campos?

A 5 de junho de 1915, no mês seguinte ao seu aparecimento e a poucos dias de ser publicado o segundo número da revista, Violante de Cysneiros envia a Fernando Pessoa uma carta que lhe chega por correio, ao escritório de Xavier Pinto \& Companhia, sito no $\mathrm{n}^{\circ} 43$ do Campo das Cebolas.

Exmo. Snr. Fernando Pessoa,

Junto envio a $V$. exa, como intermediário do Sr. Álvaro de Campos, que não sei se estrará em Portugal, algumas produções poéticas da minha autoria.

${ }^{4}$ Espólio de Côrtes-Rodrigues, cx.4-44, p.6
Abusando da penhorada amabilidade de $V$. exa., rogava-lhe a fineza de as submeter ao critério do sublime autor da "Ode Triunfal" e, se porventura, ele me fosse favorável - o que não creio muito grata ficaria. Se V. exa. me pudesse obter a sua inserção nas colunas do Orpheu.

Com minhas desculpas e toda a consideração, subscrevo-me de V. exa como a mais humilde admiradora e serva muito dedicada.

Violante de Cysneiros

Como podemos ler, esta figura feminina pede ao seu destinatário que interceda por ela junto do senhor Álvaro de Campos, que lhe parece estar fora do país, para lhe dar a ler os poemas que envia e obter dele, «sublime autor da "Ode Triumphal”, o parecer favorável que lhe permitiria a colaboração em Orpheu 2. Não sabemos quem escreveu a carta, poderá ter sido Fernando Pessoa ou CôrtesRodrigues, porém a caligrafia que emerge dela é um cursivo inglês redondo e definido, bem próximo do traço de Côrtes-Rodrigues.

Violante de Cysneiros mora em Lisboa, no número 20 da Costa do Castelo, habitando, portanto, num/um espaço medieval e, talvez não por acaso, vizinha de Afonso Lopes Vieira, poeta da tradição e da divulgação da literatura portuguesa deste período histórico, que morava no $\mathrm{N}^{\circ} 45$.

Segundo Ana Maria Binet, o apelido Cysneiros remete para o cardeal franciscano da corte dos reis católicos de Espanha, Cisneros, no qual Fernando Pessoa se poderá ter inspirado por referência à grande religiosidade do poeta açoriano e, acrescentamos nós, ao seu franciscanismo. Segundo esta 
docente da Universidade de Bordéus, o facto de Cysneiros estar grafado com "y" poderá ligar-se à ordem do cisne, cujos membros, nobres, juravam celebrar as festas consagradas à virgem, pela qual o poeta açoriano era devoto, notando ainda, que o cisne é o símbolo do movimento modernista hispânico.

Ainda que haja, e estamos certos que há, "ascendência" hispânica na "poetisa" de Orpheu, temos para nós que ela é ilhoa, tal como Côrtes-Rodrigues. É Aliete Galhoz quem o refere na introdução a Orpheu 2, sensibilizando açoriano o seu nome e, embora não apresente razão, ela está implícita nas referências ao espaço ilhéu que perpassa pelos versos deste feminino em Orpheu.

Poética açórica aparte, Violante, nome aceite por Côrtes-Rodrigues, é também nome cimeiro da História de Portugal e símbolo do patriotismo português, elementos debilitados por alguns erros dos governantes da $1^{a}$ República, e, como sabemos, atitude rejeitada pelo grupo órfico, em particular por Pessoa e Côrtes-Rodrigues. Foi Violante do Canto, abastada aristocrata terceirense que, contrariando os seus pares, apoiou, alimentando e dando aquartelamento, as tropas de António, Prior do Crato na sua resistência contra Filipe II. Com a derrota do proclamado rei António I de Portugal e a invasão da Ilha Terceira, Violante do Canto foi levada para Espanha, encerrada em mosteiros e, mais tarde, obrigada a casar com um fidalgo castelhano, morrendo sem deixar descendência.

Tudo em Orpheu é pensado, porque tudo é elemento integrante de um universo dramático em construção. Portanto, ainda que possa ser especulativo, eis, pois, em nosso entender, onde poderá encontrar-se a génese do nome Violante, a descendente dramática de Violante do Canto, ora renascida do nevoeiro, fénix sebastianista revelada no Império da Poesia que Orpheu criava.

Como se constata, havia, sem dúvida, uma "construção dramática", deveras "subtil", que se estruturava, com "Fernando Armando Violante de Cysneiros", Pessoa ensaia o drama em gente a outra dimensão. No caso, com o companheiro Côrtes-Rodrigues, aquele que, de todos, "melhor e mais de dentro o compreendia", conforme regista na página do seu diário de 21 de novembro de 1914.

E Côrtes-Rodrigues continua em Orpheu 3.

O terceiro número de Orpheu deveria ter saído em outubro de 1915 e, como sabemos, não aconteceu. Em fevereiro de 1916, o poeta açoriano regressa a S. Miguel, mas não sem antes deixar com Fernando Pessoa a sua colaboração para Orpheu 3. "Cavalgada de Sonho", assim se chama o poema com que Côrtes-Rodrigues participaria neste número da revista que não chegara a conhecer publicação.

Com a morte de Sá-Carneiro o índice da revista sofre alterações, conforme podemos constatar na carta de 4/5/1916 que Fernando Pessoa envia a Côrtes-Rodrigues em que lhe comunica o suicídio do autor de Dispersão:

Naturalmente Orpheu publicará uma plaquette, colaborada só pelos seus colaboradores, à memória do Sá-Carneiro. Logo que v.[ocê] puder, portanto quanto antes melhor - v.[ocê] mande-me qualquer coisa (o mais esmerado possível) à memória dele. Não se esqueça. O bom era que o mandasse pelo próximo vapor. (PESSOA, 1985, p.68). 
Côrtes-Rodrigues, como sempre, responde prontamente ao amigo. E, na carta que lhe envia, que torna publica no jornal Autonómico, anexa o poema "Cortejo Trágico" para integrar a tal "plaquette" com que Orpheu 3 homenagearia o companheiro morto.

O tempo passou, a revista não conheceu terceiro número e, para além deste facto, Côrtes-Rodrigues sabe somente que isso constituiu angústia para Fernando Pessoa, que, em 4 de agosto de 1923, lhe escreve, falando da sua saudade, “(...) - cada vez mais tanta! - daqueles tempos antigos do Orpheu, do Paùlismo, das intersecções e de tudo o mais que passou!" (PESSOA, 1985, p.71).

Não passou.

Porém, neste tempo, o fulgor de Orpheu já se perdera, a morte levou alguns, a vida encarregou-se de afastar outros, como foi o caso de Côrtes-Rodrigues. Este afastamento levou a que Fernando Pessoa perdesse também o contacto sobre o que se passava na vida pessoal e coletiva deste companheiro.

Em setembro de 1921, o poeta açoriano chega à Terceira, uma vez que aí foi colocado como professor. Por este tempo saiu desta Ilha com destino à capital o jovem Vitorino Nemésio que encontraria na sua Lisboa iniciática “(...) uma modernidade tímida que deixara morrer Orpheu(...)” (NEMÉSIO, 1974, p. 24)

Porém, Orpheu não morrera.

Em Lisboa, Fernando Pessoa, embora sozinho, continuou o projeto, iniciado dez anos antes, de lançar a arte portuguesa na vanguarda da cultura europeia, inscrevendo a sua universalidade através daquilo que lhe era individual. Em S. Miguel, o poeta açoriano sabe que as verdadeiras conquistas políticas passam pela afirmação cultural, pelo que, implicado no Movimento Autonómico, vive na sua poesia, como no resto da sua intervenção cultural, o seu «sentimento açoriano», ou seja, chama a si a tarefa de revelar a identidade açoriana, missão que o acompanhará até ao último dos seus dias, tal como ao companheiro lisboeta.

O projeto cultural de Orpheu acompanha, portanto, Côrtes-Rodrigues, mas, porque em outro tempo e espaço, de outro modo. Com efeito, há que ter em conta que, embora as ilhas açorianas sejam parte integrante de Portugal e, portanto, do seu ser, a realidade social e, sobretudo, política e cultural vivida no continente e nas ilhas é, neste tempo, bastante diferente. Pelo que o modo de realizar o desígnio do Homem Novo, o Homem que emergira na senda de Orpheu, seria diferente no espaço continental e no espaço ilhéu.

Portanto, ao contrário do que alguma crítica entendeu da produção poética de Côrtes-Rodrigues, neste tempo, afastando-o do Movimento de que foi parte integrante, defendemos que, quer a sua produção poética, mas, sobretudo, a sua ação cultural, seguiram os caminhos que ele iniciara na década anterior. O que deciframos na poesia e em particular no teatro de Côrtes-Rodrigues é semelhante ao que, neste tempo, o Brasil manifesta na sua arte, ou seja, o retorno às raízes, a revelação da linguagem falada do povo, a constante telúrica e o tema da diáspora.

Posto isto, ousamos afirmar que a produção poética de Côrtes-Rodrigues deste período, que a receção crítica continental de Gaspar Simões rotulou, depreciativamente, 
de Literatura regionalista, é uma outra face do Modernismo português, semelhante ao que caracterizou este Movimento no Brasil.

Doze anos depois, em novembro de 1935, Fernando Pessoa termina o texto, publicado na Sudoeste, que vimos citando, afirmando: "Orpheu acabou, Orpheu continua". E, de facto, Orpheu continuou como continuaram em Orpheu os que o construíram e nele se construíram, como é o caso do poeta que é «directamente de Orpheu». Neste texto, que se revelaria de despedida, Fernando Pessoa, que, depois de Orpheu, só se encontrou com Côrtes-Rodrigues uma única vez em 1928, num momento particular da vida do poeta açoriano, transmite-lhe, ainda, o "desejo" de que

(...) se não embrenhe demasiado, como de há tempo se vem embrenhando, no catolicismo campestre, pelo qual facilmente se aumenta o número de vítimas literárias da pieguice fruste e asiática de S. Francisco de Assis, um dos mais venenosos e traiçoeiros inimigos da mentalidade ocidental.

Côrtes-Rodrigues toma conhecimento deste "desejo" e recebe-o, conforme podemos constatar pelo que diz numa carta que escreve a Eduíno de Jesus, vinte anos depois: "Eu merecia o beliscão e aceito-o com a amizade sincera de quem mo deu. Mas o nosso pai S. Francisco é que não merecia a dureza e injustiça destas palavras (...)" (CÔRTESRODRIGUES, 2002, p. 157). E a João Afonso, a propósito da crítica por ele feita à Antologia organizada por Eduíno de Jesus, esclarece: "Pessoa chamou a esses poemas", referindo-se a Violante de Cysneiros, “"uma maravilha subtil de criação dramática' - não me envaidece a citação. E sinto que se me tivesse perdido, ter-me-ia encontrado nela." (CÔRTESRODRIGUES, 1956)

E, na verdade, como apresentámos, Côrtes-Rodrigues, o poeta que "é diretamente de Orpheu", nunca se afastou do Movimento de que foi parte integrante; e, como afirma, mesmo que o tivesse feito, as palavras do amigo Fernando Pessoa seriam, só por si, bastantes para que o reencontro acontecesse.

\section{REFERÊNCIAS}

\section{ALMEIDA, Anabela. As constantes de Orpheu} na obra de Armando Côrtes-Rodrigues. 2014. 298 f. Tese (Doutoramento em Estudos Portugueses/Estudos da Literatura) Faculdade de Ciências Sociais e Humanas. Universidade Nova de Lisboa, Lisboa.

CÔRTES-RODRIGUES. Diálogo com o Poeta Armando Cõrtes-Rodrigues, Armando, 0 Primeiro de Janeiro, Porto, 28/10/1953, p.3

. Uma carta de de Côrtes-Rodrigues a João Afonso, Atlântida -órgão do Instituto Açoriano de Cultura, Angra do Heroísmo, $\mathrm{N}^{\circ} 2$, Out-Nov. 1956, pp.114-118.

Armando Côrtes-Rodrigues e Eduíno de Jesus: Correspondência. Ed. Fernando Aires. Ponta Delgada: Museu Carlos Machado, 2002. NEMÉSIO, Vitorino. Jornal do Observador, Lisboa: Verbo, 1974.

PESSOA, Fernando. SUDOESTE, edição facsimilada. Org. Nuno Júdice. Lisboa: Contexto, 1982, p.5.

Cartas a Armando Côrtes-Rodrigues.

Intr. Joel Serrão. Lisboa: Livros Horizonte, 1985. 
SÁ-CARNEIRO, Mário. Cartas inéditas de Mário de Sá-Carneiro a Armando CôrtesRodrigues, Seara Nova, Lisboa, XXV, Nº68, 2/3/1946, pp.135-136

Recebido para publicação em 5 dez. 2016.

Aceito para publicação em 10 jan. 2017 